American Journal of Applied Sciences 7 (10): 1412-1419, 2010

ISSN 1546-9239

(C) 2010 Science Publications

\title{
Cultural Identity Expressions through Visual Analysis in Post-Disaster Housing
}

\author{
Asal Kamani Fard, Mohd Hamdan Ahmad and Dilshan Remaz Ossen \\ Department of Architecture, Faculty of Built Environment, \\ University Technology Malaysia, 81310 UTM Skudai, Johor, Malaysia
}

\begin{abstract}
Problem statement: The incidence of natural disasters as well as followed human beings' efforts for reestablishing life is considered as unavoidable essence of nature. Whilst, the interdisciplinary theme of post disaster recovery and reconstruction has been researched worldwide in order to examine its different aspects. And within architectural interests, evaluating the housing reconstruction programs would lead to beneficial clues through which useful lessons may be learnt in terms of reconstruction management while facing such unexpected challenges. Approach: This study aimed to present the visual results of the field work survey based on the mixed method research regarding post-Bam 2003 earthquake housing reconstruction efforts. In fact, the whole study was designed to find out the relation between the attitude of survived households toward their new built homes and the degree of their participation in housing reconstruction process. The focus was on analyzing the selected captured photographs provided to support the findings as documentation of research observations. Results: Accordingly, photographs were organized in to certain categories used as a mode of interpretation within the structure of visual research method analysis. The results indicated that despite different meanings of home to households, their active participation in new housing would accelerate the recovery process from sense of loss caused by catastrophes. Besides, hereby the visual and abstract tools and objectives used by households in order to express their feelings and attitude toward new built homes was addressed within defined method. Conclusion: The results indicated that despite various limitations causing change in local housing pattern following Bam earthquake, residents have attempt to express their cultural identity in some degrees as linkage to lost settings.
\end{abstract}

Key words: Bam earthquake, cultural identity, reconstruction, catastrophic disasters, social anthropology, interdisciplinary study, post-disaster housing

\section{INTRODUCTION}

The city of Bam, located in the southeast of Iran was hit by a destructive earthquake of $6.6^{\circ}$ magnitude in December 2003. The causalities of this quake made it as one of the catastrophic disasters in the recent history of the country. Due to the quake almost one third of the population were killed and the physical fabric of the city was vastly damaged and demolished. And people were affected in many aspects of economic, social and psychological terms. Besides all causalities, the ruination of more than ninety percent of residential buildings was a real challenge for survivors after the shock.

Regarding the high range of emergency and relief aid, many people from all around the world participated in respond to people's needs. Also different nongovernmental international organizations were involved in the reconstruction programs following temporary phase of the recovery process. Housing Foundation as the official governmental agency was regarded as the coordinator of post-Bam quake reconstruction efforts. Accordingly, the city was divided to different zones and the branches of Housing Foundation organized within financial and administrational supports of other provinces of the country were involved in the initial stages of housing program. Households were assisted to prepare needed documents and they were introduced to registered consultants and contractors to start the housing process. Monitoring engineers were following up all stages to ensure that the physical structures of new houses are based on approved building codes and standards. And households could receive allocated loans and grants gradually due to the approval of Housing Foundation.

Through the reconstruction strategy residents were able to select their preferred design among prepared drawings or to order for their desired plan which had to

Corresponding Author: Asal Kamani Fard, Department of Architecture, Faculty of Built Environment, University Technology Malaysia, 81310 UTM Skudai, Johor, Malaysia Tel: +60163439220 
pay additional fees for it. However, most residents had chosen available designs due to the time table limitations for receiving loans and grants. Also, the difficulties of living in temporary houses forced them to start reconstruction as soon as possible while ignoring the significance of design selection. Today, almost seven years after the earthquake, the new Bam is reconstructed and residents experience living in an environment differing from their lost setting. Addressing the home loss challenge following the disaster, this study aims to evaluate cultural identity expressions through visual analysis of new built houses as a means of coping skills within holistic rehabilitation and recovery process.

\section{Literature review:}

The significance of home place and cultural concerns: Human being tends to establish roots in the place and home is regarded as the best context to fulfill this deep demand. Hence, despite his ability to move and live everywhere, he may feel devoid of life's meanings and essence (Ralph, 1976). Chow and Healey (2008) remark that housing as a complex entity not only is derived from cultural, socio-demographic, psychological, political and economic factors of the society, but also defines mentioned items. Thus, he concludes that it contains a personal meaning which means different to each person at different times and in different context. Accordingly, Ralph (1976) suggests that same place may mean and seem different to individuals due to their personality, memories, emotions, imaginations, experiences, situations and intentions.

Also home place encompasses certain symbolic characteristics within self identity, continuity, effective anchor, personalized place and sentimental values. Whilst, it could also be regarded as the source of some pragmatic factors such as privacy, protection, base of social network and place of family relations addressed in psychological implications (Arie, 1997). And Lawrence (1987) has categorized cultural dimensions of house in following arrangement that successful combination of these terms with social and psychological dimensions would provide the definition of the home:

Cosmic image, Kinship norms and rules, House layout and orientation, House construction method, Domestic life style, Language [clean/dirty, front/back, public/private], Social and domestic rituals, Implicit rules [convention/norms], Explicit rules [building regulations] and Shared values [extant and historic].

On the other hand, places have great capacity for influencing on people's characteristics and shape their behaviors toward the environment in long and short term periods as well (Steele, 1981). Thus, he suggests two aspects of "Sense of place" as the experience of people in a setting and "Spirit of place" as the characteristics which leads to a special feeling in a setting as definition of a particular place. Moreover, Jabareen (2005) highlights the significant role of home place in defining both personal identity and bonds with community for residents all over the world. Also Steele (1981); Hay (1998); Gustafson (2001); Stedman (2002); Mitty and Flores (2009) and Knez (2005) are among scholars who have presented definitions regarding the sense of place theory and discussed about associating variables and measures. Reviewing related literatures lead this study to examine place identity as the main means of cultural expression in new built houses of research context.

Home loss challenge and holistic reconstruction efforts: Arie (1997); Barnes (2006); Cox (2006); Carroll et al. (2009); Barnes et al. (2009); Kamani Fard et al. (2010a) and Lyons (2009) are among many researchers who have addressed the global challenge of home loss after disasters. Investigating on different aspects of residents' lives, they have analyzed the conflict of housing reconstruction following relief phase. However, the main patterns of sheltering and housing are similar around the world and almost same challenges face to disaster victims (Quarantelli, 1995). And the wake of tragedy followed by architecture is regarded as one of the contents of the universal pattern of shelter provision after disasters (Davis, 1978). Thus, it is observed that survivors tend to behave and react to disasters in a uniform pattern historically. And comparing different cases, Davis (1978) has concluded that the rate of temporary houses in the list of survivors' preferences is very low.

Deeper impression of social values and culture in coping process is discussed by Oliver (2006); Gaillard (2007) and Saeng-Ngam et al. (2009) as the clue in the future life of communities. Besides, Geipel (1991) and Passerini (2000) have argued about the role of optimistic attributes associating with home loss cope toward the windows of opportunities by reconstructing desired buildings. There are also some models in disaster recovery projects suggested by Lindell and Perry (2000), Sorensen and White (1980) and Hass et al. (1977) through which the adjusting attributes of survivors and the impressive social and personal factors are defined within examined frameworks. Whilst, El-Masri and Kellett (2001); Shaw (2003); Davis (2006); Davidson et al. (2007); Baradan (2008) and Lyons (2009) have highlighted the role of survivors' participation in housing reconstruction after disasters. It is argued that 
such involvement would accelerate the recovery process from sense of loss through expressing desires and seeking for their perceived home place.

Linking the vulnerability factor to existing livelihood conditions through characteristics of society and its culture is regarded as an urgent matter (Mubarak, 2007). Therefore, cultural and ecological considerations are the main issues in both pre and post disaster management plans (Chang et al., 2006). Whilst, two considerable options are modified in disaster reconstruction process: building the city as it looked before or to use this opportunity and meet future visions through creating a new place based on cultural values of affected people.

Moreover, three different theoretical frame works are modified concerning resilience and vulnerability of traditional societies within the respond to natural hazards (Gaillard, 2007). Accordingly, survivors' capacities and attitude toward external aids would determine the degree of cultural consequences after disasters. Accordingly, while resorting on external acculturating aid, the community may face two main situations: Catalyst of pre-existing change or even cultural change. On the other hand, temporary sociocultural adjustments would lead to achieve the cultural continuity. Thus, due to the significance of home place in manifesting and protecting cultural values, present study attempts to examine such expressions regarding new built houses following 2003 Bam quake reconstruction project as well.

\section{MATERIALS AND METHODS}

Evaluating post-Bam earthquake reconstruction program, residents' efforts within cultural identity expressions in their new built houses is studied through visual analysis. Based on Rapoport (1981), identity is defined through distinctiveness that means the condition of being one thing and not another. Accordingly, as people establish their own differences with others and realize their presence, they tend to be understood through some environmental cues. Communicating and presenting mentioned cues to intended receivers of their own local community (self identity) and others (social identity) is called expression. Thus, settlement pattern, landscaping, dwelling and semi-fixed elements are regarded as means of expression.

Accordingly and due to the research objectives within studying residents' efforts through cultural identity expression, four main set of features are modified to be addressed (Mustafa et al., 2010). Thus, examining the signs of continuity in both exterior and interior of post-disaster built houses, mentioned features are defined as façade, interior setting, decorative and memorable items and garden.

For instance, visual records generated by camera are used as means of research documentation. Developed by social anthropologists, recently researchers from different fields of environmental, science and interdisciplinary studies have also been interested in visual enquiry. Emmison (2004) has highlighted the significance of direct observation as valuable efforts to explore social and cultural aspects of life. In fact, visual materials are source of data for analysis process based on research objectives rather that a mode of presentation.

Hence, three hundred sixteen photographs were captured from one hundred twenty houses in different parts of the city. The target samples have been selected from owner built houses who had more opportunity to participate in reconstruction process. And photos have been sorted based on the modified categories due to the research objectives for further analysis. Certain photograph examples representing majority of observed cases would be included in this manuscript.

Sampling procedure was based on the studies of Kuwata et al. (2005) on distribution of damages and causalities in Bam region following the disaster. Mentioned survey presents map and documents through which three zones are defined due to the level of residential destruction. Thus, a stratified random sample selection of our study has provided same probability to analyze forty houses from each zone. In fact, such selection would enable us to study the efforts of different groups of residents who had lived in various types of buildings regarding their house strength, style and location.

\section{RESULTS}

Built environment could be regarded as the demonstration of the way through which people have established and protected their cultural identity. As stated by Rapoport (2000), such expressions in recent buildings are more complicated in comparison to traditional types. Thus, nowadays different people are more concerned and sensitive about personalizing their homes. Categorizing different aspects of post-Bam quake housing reconstruction efforts in following terms, residents' approach to their new houses would be explained.

Façade: The façade of the house is regarded as the immediate sign of self and social identity expression visible to others. Representing symbols and hidden 
meanings, geometric shapes have been rather than tools to create places in traditional architecture (Ardalan and Bakhtiar, 1973). However, the shapes and forms are simplified in new built houses following the disaster (Fig. 1a).

Moreover, some of the fundamental elements (e.g., porch) as the main feature of lost dwelling style are neglected in new designs (Fig. 1b). This part, playing an important role in social contacts of residents with neighbors and friends, was also considered as a favorable place among local people (Kamani Fard et al., 2010b). Family members were used to sit and watch the garden while doing their daily activities there as well. And performing as a semi-open space, porch was an essential element as shade provider protecting windows from heat.

Due to the climate condition and local architectural styles in this region, bricks have been traditionally used as the main material of façade as signs of local styles' continuity. Besides, traditional housing had been successful in terms of providing convenient thermal condition for residents through using appropriate natural cooling systems and local materials. Although brick is still the most common used material in majority of new built houses, there are also few cases observed using some new materials (e.g., glass) ignoring climate condition (Fig. 1c).

New materials such as cement plaster that may not be based on cultural housing style are also observed in some cases (Fig. 1d). And the additional motifs are regarded as imported features while housing reconstruction. Mentioned styles and features present an obvious change in local patterns of housing and residents' preferences.

Interior setting: Although general design of most houses look like each other due to the similar interior and exterior layouts, each house presents a different image. Hence, living rooms containing furniture, pictures, family photos and valuable or decorative objects as modes of expression would provide clues to understand residents' cultural concerns. In other words, interior arrangement of living rooms presents an overview of family life.

On the other hand, personalization could be regarded as the manifestation of residents' strong sense of attachment to their homes. Accordingly, despite almost similar designs of house layouts, using various interior arrangements and styles presents different views of the houses (Fig. 2a). As a matter of fact, for some people rebuilding the house was an opportunity to access modern facilities and a more comfortable life (Fig. 2b).
They also tend to arrange the interior setting based on their taste using different styles of furniture and decorations. However, some other have not accepted the change yet and tried to adapt new designs with their cultural values. For example, some ladies prefer not to be seen by guests while working in the kitchen and due to cultural concerns. Thus, they use mobile partitions separating open kitchen from the living room in certain occasions (Fig. 2c).

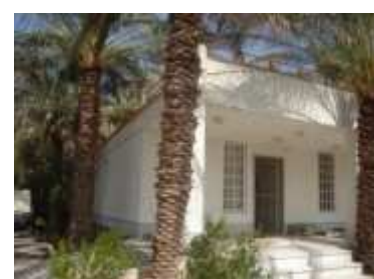

(a)

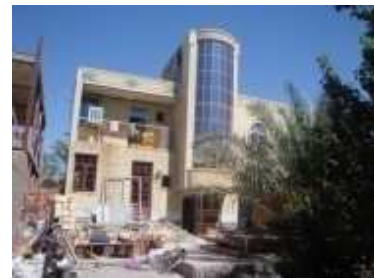

(c)

Fig. 1: Façade

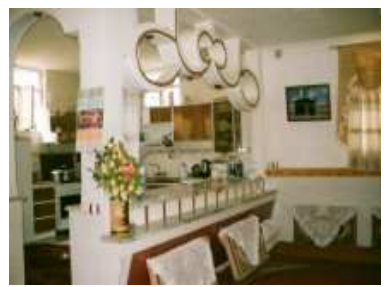

(a)

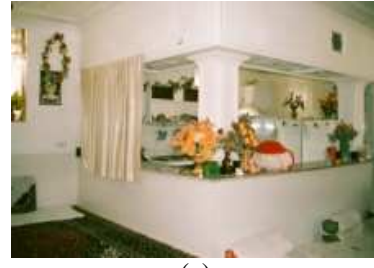

(c)

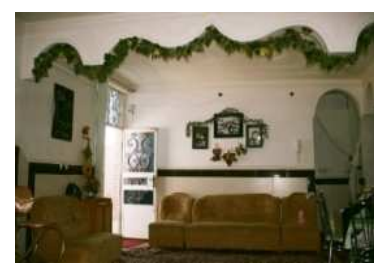

(e)

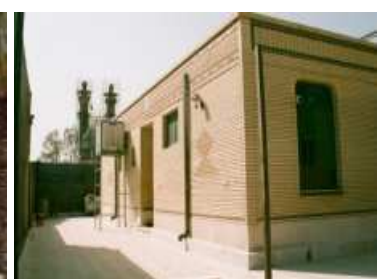

(b)

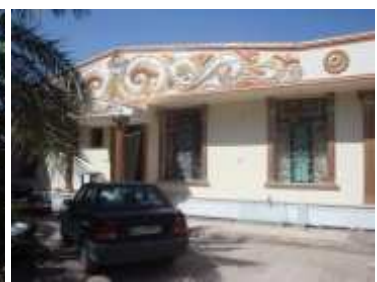

(d)

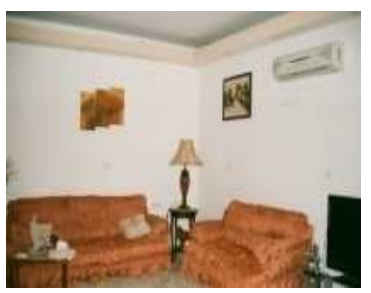

(b)

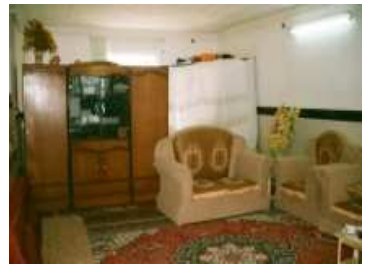

(d)

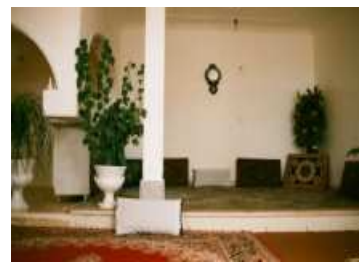

(f)
Fig. 2: Interior settings 
Besides interior layouts of the house, the impression of new settings' size on life style of people must be considered as well. The notable change in the size of new built houses which is due to financial limitations seems to be a real challenge for resident. Traditionally, local people have been used to live in large houses which might be built gradually within years. Thus, dealing with small spaces and managing daily activities as well as social relations is a serious issue while trying to divide small space for certain purposes (Fig. 2d).

Photos of lost family members on walls are the other common view observed in most of the houses. It makes residents feel connected to the memories of past (Fig. 2e). In addition, the tendency to live in an exactly same interior setting with lost home is observed (Fig. 2f). Due to residents, to live in such setting with similar furniture arrangement would provide a familiar place leading to the sense of continuity.

Garden: Due to the climate and cultural context of Bam, gardens have been traditionally well concerned in this hot and dry climate. Considered as the most favorable part of the local houses, many of daily activities have been traditionally done in green environment of the gardens. In addition, the presence of palm dates in many aspects of cultural and economic life of residents has led to establish their deep sense of attachment among them to nature (Fig. 3a). Also the spatial arrangement of building and garden was providing beautiful views in the lost houses.

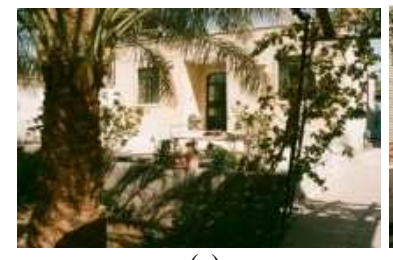

(a)

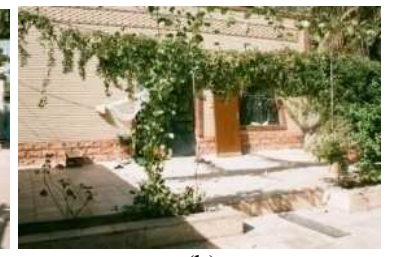

(b)

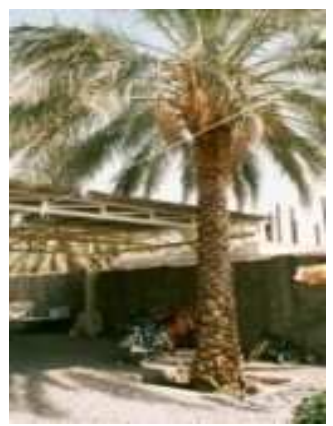

(c)

Trying to remind familiar views and nice memories of lost homes, some of the residents have special concerns about garden setting (Fig. 3b). In fact, such attempts would recreate the sense of attachment to their new house. However, in majority of cases expected attention was not paid to gardens due to the financial limitations (Fig. 3c). And despite residents' awareness regarding its great positive role in provision of vitality and good sense, garden is the neglected part of most of the house.

Memorable and found items: Recreating similar interior settings with lost homes is an attempt to provide the sense of continuity in new built houses. Accordingly, memorable and valuable items found among ruins of lost homes are also considered as a linkage to the past. And despite the fact that some people prefer living in totally different settings to forget sad memories of past, others tend to use reminder signs of lost homes.

Most of Persian families would like to keep different types of favorite dishes or carpets as decorative objects in their homes. Asking the residents about found memorable items, some happily point to certain objects treated carefully in new setting (Fig. 4a). Such items are valuable to them regardless their condition and price reminding past days (Fig. 4b). In addition, those who were not able to find nothing have expressed their deep sorrow while being requested to show found items.

Decorative items: The geographic location of the country besides the symbolic meaning of light in ancient beliefs of locals have made them highly sensitive to light, shade, shadow in buildings (Ardalan and Bakhtiar, 1973). Additionally, people are well concerned about colors as the result of light reflection. In fact, they tend to express such symbolic meanings through every detail in art and architecture. It could be observed in miniatures, carpets and also tiles as seeking for unity through light polarization.

Despite differentiations in terms of decorative objects used in new houses-as mentioned previously within interior setting section-, various features are used as means of cultural expressions. Decorative gypsum works (Fig. 5a) and colorful tiles containing traditional miniature paintings (Fig. 5b) are of such examples.

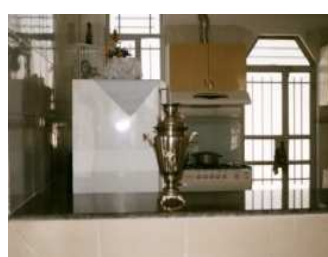

(a)

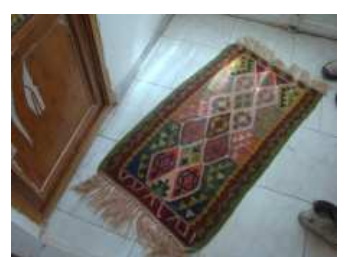

(b)

Fig. 3: Garden

Fig. 4: Memorable and found items 


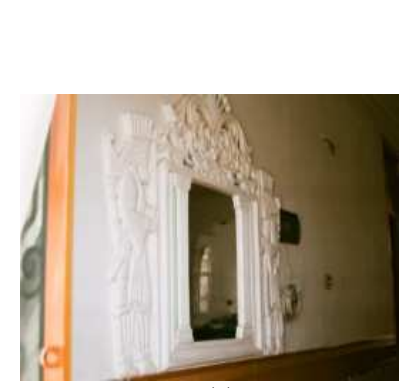

(a)

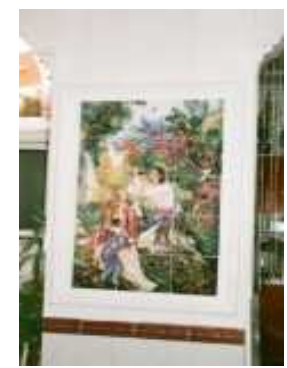

(b)

Fig. 5: Decorative items

\section{DISCUSSION}

Containing the local values buildings express traditions through both symbolic and formal language (Oliver, 2006). Such expression would provide the sense of continuity by linking past to future. This issue would be more highlighted while rebuilding houses following the destruction caused by disasters. For instance, housing is considered as the cultural resuming means of local communities while transmission periods (Rapoport, 2000). However, "cultural issues relating to the provision of housing, reflecting family size and structure, hierarchies, religious beliefs and values, customs and traditions that are essential to specific cultures are frequently overlooked in temporary, as well as permanent, post-disaster re-housing" Oliver (2006).

On the other hand, new materials, construction techniques and survivors' expectations are regarded as factors interrupting the cultural continuity in housing. Whilst, considering safety standard besides varieties of local cultural values would lead to achieve holistic solutions (Alexander, 1989). In the words of Oliver (2006), "Under the suffering and stress of a major disaster, people can react in ways that may reject or accept all help, including post-disaster housing. Subsequent reactions may appear perplexing, even irrational, but they can reveal the persistent values by which a culture reclaims its identity". In fact, physical, cultural and perceptual factors affect the degree of significance of certain features in form, structure, space use, or detail in buildings which may change over time due to the innovations or different accepted norms.

\section{CONCLUSION}

Almost all over the world house is considered as an important part of one's asset. In other words, house is the main source of sense of belonging for most of people. However, it may take many years to own a house depending on the economic, social and even political situation of each community. Thus, its destruction following a disaster is a real challenge faced by survivors. This conflict not only affects the physical structure and economy of cities and communities, but also may change the socio cultural and psychological norms.

Supporting the reviewed literature, this study confirms that changes in housing patters are unavoidable due to overall conditions following disasters. However, regarding post-Bam quake reconstruction, residents' efforts within reestablishing cultural values are observed as signs of continuity. Accordingly, despite similarities in designing layouts of the houses, residents have left their individual stamps on the houses expressing their identity. Beside, such expressions could be considered as significant linkage to their lost settings. In addition to personalizing both exterior and interior of living spaces, residents have also taken some adaptation modes while dealing with new settings.

As a matter of fact, there are parallel benefits and advantages for architecture itself while seeking the most appropriate solutions within post-disaster housing programs. Hence, it is argued that this challenge could be regarded as an opportunity not only for the affected community to attain better facilities, but also for designers to achieve more holistic house types associating in recovery process.

\section{REFERENCES}

Alexander, D., 1989. Preserving the identity of small settlements during post disaster reconstruction in Italy. Disasters, 13: 228-236. DOI: 10.1111/j.14677717.1989.tb00712.x

Ardalan, N. and L. Bakhtiar, 1973. The Sense of Unity: The Sufi Tradition in Persian Architecture. 1st Edn., University of Chicago Press, US., Chicago, ISBN: 0226025594, pp: 172.

Arie, J., 1997. Motivation in elderly disaster victims during recovery from loss of home. Ph.D. Thesis, Texas A\&M University.

Baradan, B., 2008. Review of literature for the concept of post disaster housing in Turkey. G.U. J. Sci., 21: 43-49.

http://www.fbe.gazi.edu.tr/dergi/tr/dergi/tam/21(2)/ 3.pdf

Barnes, B., H. Cao, T. Drab and J. Pearson, 2009. Design of sustainable relief housing in Ethiopia: An implementation of cradle to cradle design in earthbag construction. Am. J. Environ. Sci., 5: 137-144. DOI: 10.3844/ajessp.2009.137.144 
Barnes, J., 2006. Developing disaster survivor resiliency: The home away from home. Disaster Prevent. Manage., 15: 223-232. DOI 10.1108/09653560610659766

Carroll, B., H. Morbey, R. Balogh and G. Araoz, 2009. Flooded homes, broken bonds, the meaning of home, psychological processes and their impact on psychological health in a disaster. Health Place, 15: 540-547. DOI: 10.1016/j.healthplace.2008.08.009

Chang, H.J., R. Hargrove, Y.X. Long and D.J. Osborne, 2006. Reconstruction after the 2004 tsunami: Ecological and cultural considerations from case studies. Landscape Ecol. Eng., 2: 41-51. DOI: 10.1007/s11355-006-0035-3

Chow, K. and M. Healey, 2008. Place attachment and place identity: First-year undergraduates making the transition from home to university. J. Environ. Psychol., 28: 362-372. DOI: 10.1016/j.jenvp.2008.02.011

Cox, R.S., 2006. Echoes, transgression and transformations: Identity reorientation and the discourse of disaster recovery. Ph.D. Thesis, The University of British Columbia. https://circle.ubc.ca/handle/2429/18234

Davidson, C.H., C. Johnsona, G. Lizarraldea, N. Dikmena and A. Sliwinskiet, 2007. Truths and myths about community participation in post-disaster housing projects. Habitat Int., 31: 100-115. DOI: 10.1016/j.habitatint.2006.08.003

Davis, I., 2006. Sheltering from Extreme Hazards. In: Vernacular Architecture in 21th Century: Theory, Education and Practice, Asquith, L. and M. Vellinga (Eds.). Taylor and Francis, New York, ISBN: 0415357810, pp: 145-154.

Davis, I., 1978. Shelter after Disaster. 1st Edn., Oxford Polytechnic Press, Headington, Oxford, ISBN: 090269216X, pp: 127.

El-Masri, S. and P. Kellett, 2001. Post-war Reconstruction. Participatory approaches to rebuilding the damaged villages of Lebanon: A case study of al-Burjain. Habitat Int., 25: 535-557. DOI: 10.1016/S0197-3975(01)00023-6

Emmison, M., 2004. The Conceptualization and Analysis of Visual Data. In: Qualitative Research: Theory, Method and Practice, Silverman, D. (Ed.). Sage Publication Ltd., London, ISBN: 076194933X, pp: 246-265.

Gaillard, J.C., 2007. Resilience of traditional societies in facing natural hazards. Disaster Prevent. Manage., 16: 522-544. DOI: 10.1108/09653560710817011

Geipel, R., 1991. Long-Term Consequences of Disasters: The Reconstruction of Friuli, Italy, in its International Context 1976-1988. 1st Edn., SpringerVerlag., New York, ISBN: 0387974199, pp: 171.
Gustafson, P., 2001. Meanings of place: Every day experience and theoretical conceptualization. J. Environ. Psychol., 21: 5-16. DOI: 10.1006/jevp.2000.0185

Hass, J.E., P.B. Trainer, M.J. Bowden and R. Bolin, 1977. Reconstruction Issues in Perspective. In: Reconstruction Following Disasters, Haas, J.E., R.W. Kates and M.J. Bowden (Eds.). The MIT Press, Massachusetts, ISBN: 026208094X, pp: 25-68.

Hay, R., 1998. Sense of place in developmental context. J. Environ. Psychol., 18: 5-29. DOI: 10.1006/jevp.1997.0060

Jabareen, Y., 2005. Culture and housing preferences in a developing city. Environ. Behav., 37: 134-146. DOI: 10.1177/0013916504267640

Kamani Fard, A., M.H. Ahmad and D.R. Ossen. 2010a. Facing home loss after disasters: A review. Proceedings of the 2nd International Postgraduate Conference on Infrastructure and Built Environment, June 1-2, Hong Kong Polytechnic University, Hong Kong, China, pp: 495-502.

Kamani Fard, A., M.H. Ahmad and D.R. Ossen, 2010b. Mitigating home loss challenge: Efforts' evaluation of Bam-quake reconstruction through the sense of place measures. Proceedings of the COBRA Conference, Sept. 2-3, Dauphine Universite, Paris, France, pp: 1-1.

Knez, I., 2005. Attachment and identity as related to a place and its perceived climate. J. Environ. Psychol., 25: 207-218. DOI: 10.1016/j.jenvp.2005.03.003

Kuwata, Y., S. Takada and M. Bastami, 2005. Building damage and human casualties during the Bam-Iran earthquake. Asian J. Civil Eng. (Build. Hous.), 6: 1-19.

http://www.bhrc.ac.ir/english/Publication/AJCE/P DF/Vol6No1-2/Kuata-1.pdf

Lawrence, R.J., 1987. What makes a house a home? Environ. Behav., 19: 154-168. DOI: 10.1177/0013916587192004

Lindell, M.K. and R.W. Perry, 2000. Household adjustment to earthquake hazard a review of research. Environ. Behav., 32: 461-501. DOI: $10.1177 / 00139160021972621$

Lyons, M., 2009. Building back better: The large-scale impact of small-scale approaches to reconstruction. World Dev., 37: 385-398. DOI: 10.1016/j.worlddev.2008.01.006

Mitty, E. and S. Flores, 2009. There's no place like home. Geriat. Nurs., 30: 126-129. DOI: 10.1016/j.gerinurse.2009.01.004

Mustafa, M.M., Daizhizhong and Y. Hong, 2010. The characteristics of architecture style of the traditional houses in the Mosul city-analytical study. Am. J. Eng. Applied Sci., 3: 380-389. DOI: 10.3844/ajeassp.2010.380.389 
Mubarak, K., 2007. Analyzing post-tsunami livelihoods recovery: The case of masons in Polhena Village, Sri Lanka. SSEE. http://www.pasi.unimelb.edu.au/research/papers/S SEE-papers/rp-02-tsunami.pdf

Oliver, P., 2006. Built to Meet Needs: Cultural Issues in Vernacular Architecture. 1st Edn., Architectural Press, Italy, ISBN: 978-0750666572, pp: 480.

Passerini, E., 2000. Disasters as agents of social change in recovery and reconstruction. Natural Hazards Rev., 1: 67-72. DOI: 10.1061/(ASCE)15276988(2000)1:2(67)

Quarantelli, E.L., 1995. Patterns of sheltering and housing in US disasters. Disaster Prevent. Manage., 4 4: 43-53. DOI: 10.1108/09653569510088069

Ralph, E.C., 1976. Place and Placelessness. 1st Edn., Routledge Kegan and Paul, London, ISBN: 0850860555, pp: 156.

Rapoport, A., 1981. Identity and Environment: A Cross-Cultural Perspective. In: Housing and Identity: Cross-cultural Perspectives, Duncan, J.S. (Ed.). Law Book Co of Australasia, London, ISBN: 0709903227, pp: 6-35.

Rapoport, A., 2000. Theory, culture and housing. Hous. Theory Soc., 17: 145-165. DOI: $10.1080 / 140360900300108573$
Saeng-Ngam, A., S. Chantachon and P. Ritthidet, 2009. The organization of cultural tourism by the community people in the region of Toong Kula Rong Hai. J. Soc. Sci., 5: 342-347. http://www.scipub.org/fulltext/jss/jss54342347.pdf

Shaw, R., 2006. Indian Ocean tsunami and aftermath: Need for environment-disaster synergy in the reconstruction process. Disaster Prevent. Manage., 15: 5-20. DOI: 10.1108/09653560610654202

Sorensen, J.H. and G.F. White, 1980. Natural Hazards: A Cross-Cultural Perspective. In: Human Behavior and Environment, Altman, I., J.F. Wohlwill and A. Rapoport (Eds.). Springer, New York, ISBN: 0306403676, pp: 279-314.

Stedman, R.C., 2002. Toward a social psychology of place predicting behavior from place-based cognitions, attitude and identity. Environ. Behav., 34: 561-581. DOI: $10.1177 / 0013916502034005001$

Steele, F., 1981. The Sense of Place. 1st Edn., CBI Publishing Company, Massachusetts, ISBN: 0843601353, pp: 272. 